\title{
High efficiency direct liquid jet impingement cooling of high power devices using a 3D-shaped polymer cooler
}

\author{
T. Tiwei ${ }^{1,2}$, H. Oprins ${ }^{1}$, V. Cherman ${ }^{1}$, G. Van der Plas ${ }^{1}$, I. De Wolf ${ }^{1,3}$, E. Beyne ${ }^{1}$ and M. Baelmans ${ }^{2}$ \\ email: tiwei.wei@imec.be \\ ${ }^{1}$ imec, Leuven, Belgium, ${ }^{2}$ Dept. Mech. Eng. KU Leuven, Leuven, Belgium, ${ }^{3}$ Dept. Materials Eng. KU Leuven, Leuven, Belgium
}

Abstract - A novel 3D-shaped polymer multi-jet impingement cooler based on low cost fabrication techniques is introduced for high performance applications. This paper presents the modeling study, design, fabrication, experimental characterization and benchmarking of this cooling concept, showing a very good thermal performance with low required pumping power.

\section{INTRODUCTION}

To cope with the increasing cooling demands for future high performance devices and 3D systems, conventional liquid cooling solutions such as (microchannel) cold plates are no longer sufficient. Drawbacks of these conventional cold plates are the presence of the thermal interface material (TIM), which represents a major thermal bottleneck, and the temperature gradient across the chip surface. Alternative advanced liquid cooling solutions have been proposed such as inter-tier [1] and intra-tier [2] cooling for 3D systems. These solutions are however not compatible with the fine pitch requirements for high bandwidth communication between different tiers of a 3D system as shown in Fig. 1. This figure shows a schematic of high performance 3D system on chip (SOC), realized by functional partitioning of the blocks in a core layer, a memory layer and a layer for IO and communication. Liquid jet impingement cooling is an efficient cooling technique where the liquid coolant is directly ejected from nozzles on the chip backside resulting in a high cooling efficiency due to the absence of the TIM and the lateral temperature gradient. In literature, several Si-fabrication based impingement coolers with nozzle diameters of a few tens of $\mathrm{m}$ have been presented for common returns $[3,4]$, distributed returns [5] or combination of micro-channels and impingement nozzles $[6,7]$. The drawback of this Si processing of the cooler is the high fabrication cost. Other fabrication methods for nozzle diameters of a few hundred $m$ have been presented for ceramic [8] and metal [9]. Low cost fabrication methods, including injection molding [10,11] and 3D printing [12] have been introduced for much larger nozzle diameters (mm range) with larger cooler dimensions. These dimensions and processes are however not compatible with the chip packaging process flow.

In this paper, we present a novel impingement based liquid cooling solution, fabricated using low cost polymer fabrication techniques, targeted to directly cool the backside of high performance chips or chip stacks, as shown in Fig. 1. The internal structure of the concept of the cooler is schematically shown in Fig. 2 revealing the distributed inlet and outlet channels for the delivery and removal of the coolant to the chip backside respectively. The purpose of this work is to demonstrate the feasibility of an integrated polymer impingement cooler and to benchmark its thermal performance with literature data for impingement coolers with various materials. In order to evaluate the thermal performance, the fabricated 3D-shaped polymer cooler is assembled to our $8 \times 8 \mathrm{~mm}^{2}$ thermal test chip [13] with integrated heaters and temperature sensors (Fig. 3). First, the modeling of the thermal and fluidic behavior and the impact of the parameters is discussed. Based on the modeling results, the cooler design is presented and finally the thermal performance and benchmarking of the fabricated polymer cooler is discussed.

\section{Modeling, Design \& FABricAtion}

Conjugate heat transfer and fluid dynamics simulations have been performed to assess the thermal and fluidic behavior of an impingement cooler with a $N \times N$ array of inlet nozzles and distributed outlets in between the inlets. A unit cell model (Fig. 4) has been used to assess the optimal number of nozzles, nozzle pitch and diameter. A model of the full cooler is used to study the interaction of the different nozzles and the impact of the thermal conductivity of the cooler material. The thermal performance is expressed in terms of the thermal resistance $R_{t h}$

$$
R_{\text {th }}=\left(T_{\text {ch,avg }}-T_{\text {in }}\right) / P
$$

where $T_{c h, a v g}$ is the average chip temperature, $T_{i n}$ is the coolant inlet temperature and $P$ is the chip power.

\section{A. Unit cell modeling results}

Fig. 5a shows that increasing the number of inlet nozzles results in a more uniform chip temperature distribution. The thermal resistance can be further reduced by increasing the flow rate, however at the expense of the required pump power (Fig. $5 b)$. The trade-off can be shown in a thermal resistance versus pump power chart in which each cooler design is represented by a curve for a range of flow rates; the closer the curve is to the origin, the better the thermal performance and the less required pumping power of the cooler is. Fig. 6a shows the evolution of the thermal performance for an increasing number of unit cells under a fixed cavity height of $200 \mathrm{~m}$. By using a high number of small diameter nozzles one can achieve better thermal performance. However, it requires a very high pressure, resulting in a saturation of the thermal performance increment beyond $\mathrm{N}=8$ ( $1 \mathrm{~mm}^{2}$ unit cell) in Fig. $6 \mathrm{~b}$. Moreover, $\mathrm{N} \leq 8$ is in the range of the capability of polymer fabrication techniques while higher nozzle numbers, and smaller diameters would require more expensive Si fabrication techniques. Furthermore, the unit cell model shows that the nozzle diameter in the chosen unit cell size should be as large as possible to optimize the thermal performance (as in Fig. 7). Table 1 shows the link between the number of nozzles, the inlet diameter and the required fabrication method. 


\section{B. Full cooler level modeling}

Fig. 8 shows the complete model of the flow distribution and heat conduction in the coolant, cooler material and chip package for a $4 \times 4$ array cooler. From Fig. 9 , it can be concluded that the impact of the thermal conductivity of the cooler material is negligible over a wide range of flow rates and chip power, since the heat removal is dominated by the forced convection in the coolant. This shows that a polymer cooler has the same performance as a $\mathrm{Si}$ or $\mathrm{Cu}$ cooler and therefore offers opportunities for the use of polymer based low cost fabrication techniques. The full model is also used to optimize the plenum height as a function of the inlet diameter to minimize flow maldistribution.

\section{Test vehicle design and fabrication}

Based on the modeling results for the number of unit cells, inlet diameter and impact of material conductivity, a simplified board level polymer demonstrator cooler with a $4 \times 4$ array of $450 \mathrm{~m}$ inlets and $5 \times 5$ array of $600 \mathrm{~m}$ outlets has been designed (Fig. 10a). The design parameters are listed in Table 2. The cooler has been fabricated in Polyvinyl chloride (PVC) using mechanical machining with a tool diameter of $500 \mathrm{~m}$ for the plenum structure and drilling for the inlet and outlet holes. Fig. 10b shows the assembly of the cooler and the mounting of the cooler on the PTCQ chip and PCB.

\section{Characterization AND BenChMarking}

The fabricated cooler is characterized for the following conditions: $50 \mathrm{~W}$ quasi-uniform chip power, inlet temperature $10^{\circ} \mathrm{C}$, coolant flow rate range from $280 \mathrm{~mL} / \mathrm{min}$ to $600 \mathrm{~mL} / \mathrm{min}$.

\section{A. Experimental thermal characterization}

The polymer cooler has been successfully mounted to the chip package and no leakage is observed. Temperature measurements are performed using the $32 \times 32$ array of diodes in the PTCQ test chip to visualize the chip temperature distribution for the quasi uniform power dissipation pattern (yellow cells in Fig.3). A very low thermal resistance of $0.25 \mathrm{~K} / \mathrm{W}$ is obtained for a flow rate of $600 \mathrm{~mL} / \mathrm{min}$ with a required pump power of $0.4 \mathrm{~W}$. Moreover, the temperature distribution over the chip is very uniform (Fig. 11). The comparison between the complete measured temperature map and the modeling results in Fig. 12 and comparison of the thermal resistance for the unit cell model, full model and measurements with different flow rates in Fig. 13 both show excellent agreement. By increasing the flow rate from $280 \mathrm{~mL} / \mathrm{min}$ to $600 \mathrm{~mL} / \mathrm{min}$, the thermal resistance can be reduced by a factor of 1.7. The measured temperature map corresponding to inlets and outlets nozzle pattern is checked in Fig. 14. Compared with a single jet cooler, shown in Fig. 15a and b, on the same chip package, the multi-jet impingement cooler results in a lower thermal resistance and a better temperature uniformity under the same flow rate as can be seen in Fig. 15c.

\section{B. Benchmarking with literature data}

The cooling performance in terms of thermal resistance and pumping power of the fabricated polymer cooler with a $4 \times 4$ array of inlets $\left(0.25 \mathrm{~K} / \mathrm{W}\right.$ or $0.16 \mathrm{~cm}^{2} . \mathrm{K} / \mathrm{W}$ for a pumping power of $0.4 \mathrm{~W}$ ) has been compared in Fig. 16 with published data in literature for impingement coolers fabricated using various ma- terials: Si [3-7], ceramic [8], metal [9] and plastic [10-12] presented in the introduction section. From the thermal resistance versus pump power benchmarking chart in Fig. 16, it can be observed that the presented 3D-shaped polymer cooler has a very good thermal performance, that is achieved with a relatively low pumping power. The thermal performance is only exceeded by the Si based cooler [5] with very fine pitch $25 \mathrm{~m}$ nozzles, however that cooler requires a $5 \times$ larger pump power. This benchmarking study clearly shows the potential of the presented polymer based cooler and proves that it is not necessary to scale down the nozzle diameters to a few tens of micron but that very good thermal performance can be obtained with nozzle diameters in the range of several hundred micrometers, which is compatible with low cost polymer fabrication.

\section{CONCLUSIONS}

In this paper, we present the concept, modeling, design, fabrication, experimental characterization and benchmarking with literature data of a novel impingement based liquid cooling solution, fabricated using low cost polymer fabrication techniques, targeted to directly cool the backside of high performance chips or chip stacks. It is demonstrated that polymer is a valuable alternative material for the fabrication of the impingement cooler instead of expensive Si based fabrication methods. The modeling results show that it is not necessary to scale up the number of unit cells and to shrink the nozzle diameter accordingly to improve the thermal performance for a fixed cavity height, making the required diameters compatible with polymer fabrication methods. Moreover, the simulations indicate that the thermal conductivity of the cooler material has no impact on the thermal performance of the impingement cooler.

A $4 \times 4$ array jet impingement cooler with 450 m nozzles has been fabricated using mechanical machining in PVC and has been assembled to a test chip package. The experimental characterization shows a very low thermal resistance of 0.25 $\mathrm{K} / \mathrm{W}\left(0.16 \mathrm{~cm}^{2} . \mathrm{K} / \mathrm{W}\right)$ and good temperature uniformity across the chip surface. The benchmarking study with literature data for impingement coolers with a large range of inlet diameters shows a very good thermal performance of the fabricated cooler for a low required pumping power.

\section{ACKNOWLEDGMENT}

This work was performed as part of the imec Industrial Affiliation Program on 3D System Integration and has been strongly supported by the imec partners and the imec Reliability, Electrical testing, Modeling and 3D technology teams.

\section{REFERENCES}

[1] T. Brunschwiler et al., Microsyst Technol., vol. 15, pp. 57-74, 2009

[2] L. Zheng et al., proc. IEEE ECTC, pp. 828-832, 2015

[3] E.N. Wang et al., IEEE J. Microelectromech. Sys., vol. 13, pp.833-842, 2004

[4] G.J. Michna et al., IJHMT, vol. 54, pp. 1782-1790, 2011

[5] T. Brunschwiler et al., proc. IEEE ITherm, pp. 193-203, 2006

[6] E.G. Colgan et al., J. Heat Transfer, vol. 129, pp. 1046-1051, 2006

[7] C.S. Sharma et al., IJHMT, vol. 8, pp. 684-694, 2015

[8] G. Natajaran et al., Heat Transfer Eng., vol. 28, pp. 779-787, 2007

[9] T. Acikalin and C. Schroeder, proc. IEEE ITherm, pp. 673-679, 2014

[10] K. Gould et al., IEEE Trans. Power Electronics, vol.30, pp.2975-2984, 2015

[11]K.Olesen et al., proc. Automotive Power Electronics, 1-9, 2006

[12]B.P. Whelan et al., Applied Thermal Engineering, vol. 39, pp. 86-94, 2012

[13]H. Oprins et al., J. Electron. Packaging, vol. 138, pp. 101902 1-10, 2016 


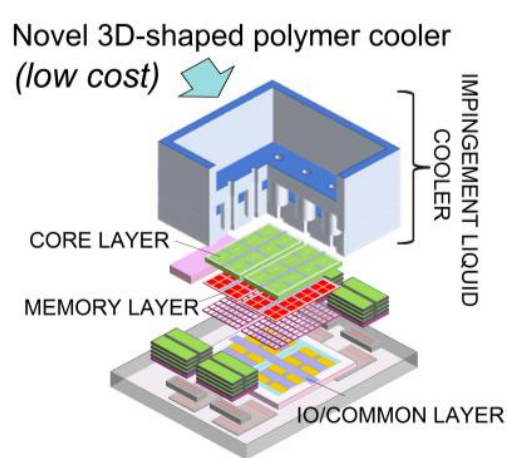

Fig. 1. Example of high performance application for the novel 3D-shaped polymer cooler. 3D functional partitioning of HPC SOC in a core layer, memory layer and $\mathrm{IO} /$ common layer.

$$
\text { (a) }
$$

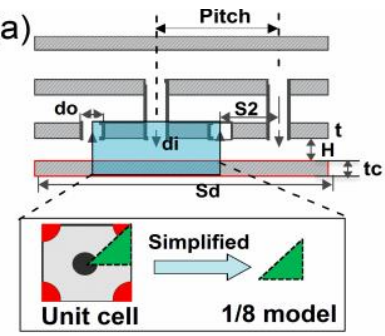

(b)

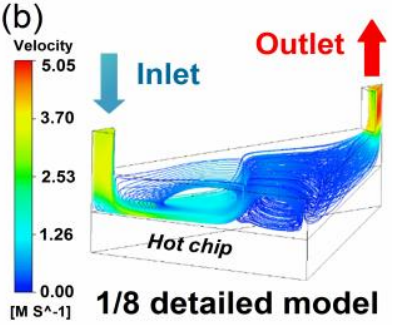

Fig. 4 Unit cell modeling approach: a) Indication of cooler geometrical parameters and unit cell; b) Coupled flow and thermal simulation result from a 1/8 detailed model, simplified from the unit cell shown in Fig. $2 b$.

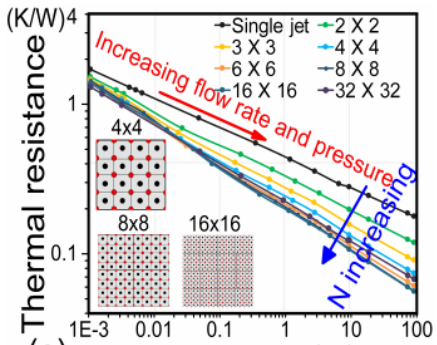

(a)
Pump power (W) (b) ${ }^{0}{ }^{5}{ }^{10}{ }^{15}{ }^{15}{ }^{20}{ }^{25}{ }^{25}{ }^{30}{ }^{35}$

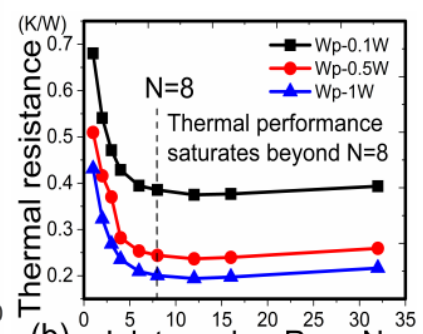

Fig. 6 Scaling of the cooler thermal performance for increasing number of inlet nozzles: a) Thermal resistance vs pump power tradeoff; b) Evolution of thermal resistance as a function of number of nozzles for constant pump power (Wp). (a)

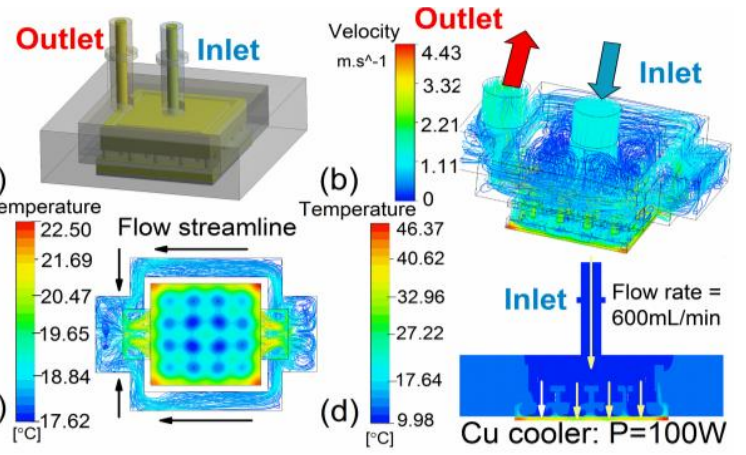

Fig. 8. Thermal and fluidic modeling with a) full model of the cooler, b) and c) show the flow field and temperature distribution of the cooling, d) shows the impact of the $\mathrm{Cu}$ cooler under $100 \mathrm{~W}$.

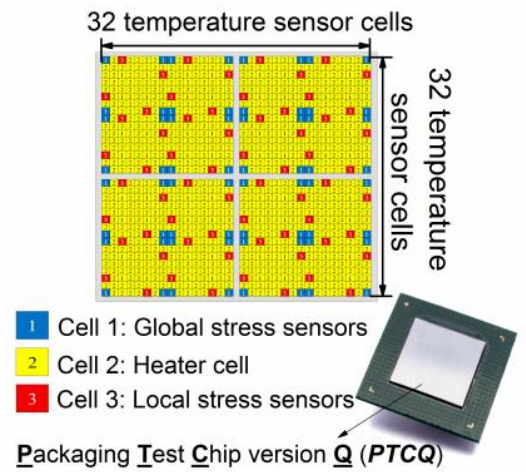

Fig. 3. Floorplan of the $8 \times 8 \mathrm{~mm}^{2}$ PTCQ thermal test chip with $32 \times 32$ array of temperature sensors and 832 programmable heater cells.
Fig. 2. Concept of the 3D shaped polymer cooler: a) Cross section of the multi-jet coole internal structure; b) Top view of the distrib-
uted inlets and outlets in the nozzle plate.
Cold plenum Hot plenum Nozzle plate mpingement

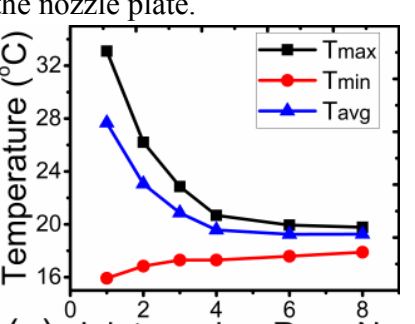

(a) Inlet number Row: $\mathrm{N}$

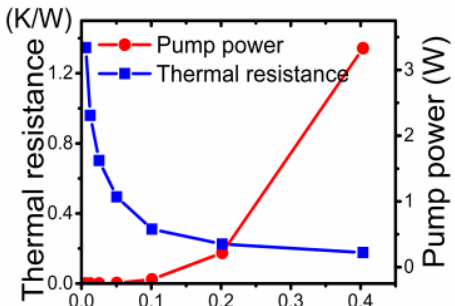

(b) Flow rate (L/min)

Fig. 5 Unit cell thermal modeling results: a) Evolution of temperature distribution as function of inlet numbers in $\mathrm{N} \times \mathrm{N}$ array; b)Tradeoff between improved thermal resistance and increased required pump power for higher flow rates. ( $N$ represents the row number of nozzle arrays)

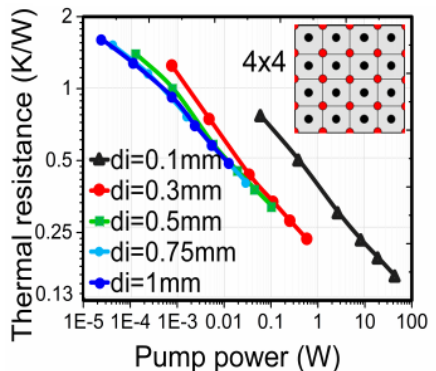

Fig. 7. Impact of inlet diameter on cooler thermal performance under di $=$ do (Inlet diameter: di; Outlet diameter: do)

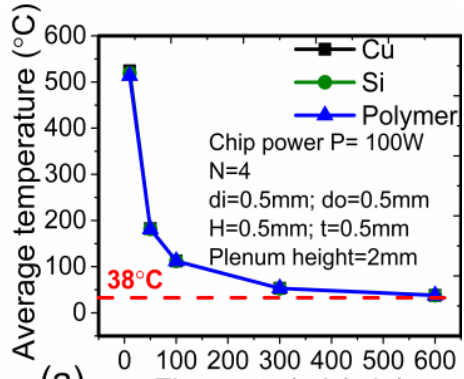

(a) Flow rate (mL/min)

\begin{tabular}{|c|c|c|}
\hline $\mathbf{N} \times \mathbf{N}$ & $\begin{array}{l}\text { Nozzle } \\
\text { diame- } \\
\text { ter }\end{array}$ & $\begin{array}{l}\text { Fabrication } \\
\text { technology }\end{array}$ \\
\hline 1 & $2.4 \mathrm{~mm}$ & \multirow{3}{*}{$\begin{array}{l}\text { Mechanical } \\
\text { machining } \\
\text { process }\end{array}$} \\
\hline $2 \times 2$ & $1.2 \mathrm{~mm}$ & \\
\hline $4 \times 4$ & $600 \mathrm{~m}$ & \\
\hline $6 \times 6$ & $400 \mathrm{~m}$ & \multirow{3}{*}{\begin{tabular}{|l|} 
Injection \\
molding/3D \\
Printing \\
\end{tabular}} \\
\hline $8 \times 8$ & $300 \mathrm{~m}$ & \\
\hline $16 \times 16$ & $150 \mathrm{~m}$ & \\
\hline $32 \times 32$ & $75 \mathrm{~m}$ & \multirow{2}{*}{$\begin{array}{l}\text { Silicon } \\
\text { processing }\end{array}$} \\
\hline $64 \times 64$ & $38 \mathrm{~m}$ & \\
\hline
\end{tabular}

Table 1. Relation between nozzle diameter and fabrication options.

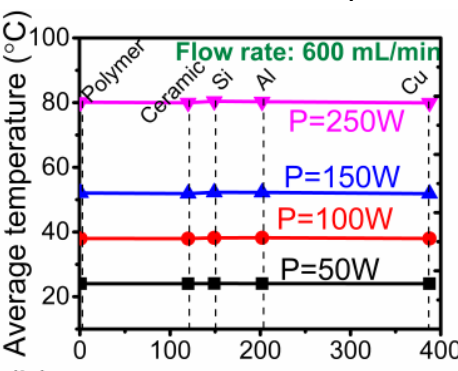

(b) Thermal conductivity $\left(\mathrm{W} / \mathrm{K} . \mathrm{cm}^{2}\right)$

Fig. 9. Impact of the thermal properties of the cooler material on the thermal performance of the impingement cooler for different a) flow rates and b) chip power levels. 
(a)

(b) Top->Bottom Bottom->Top

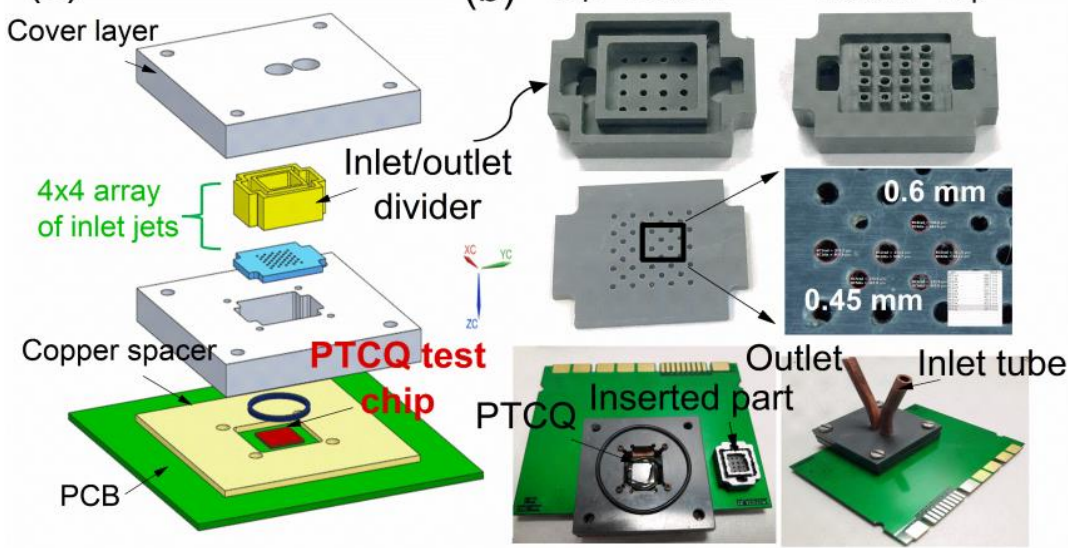

Fig. 10. Design (a) and photographs (b) of the $4 \times 4$ array demonstrator of the impingement cooler and integration on the test chip and PCB.
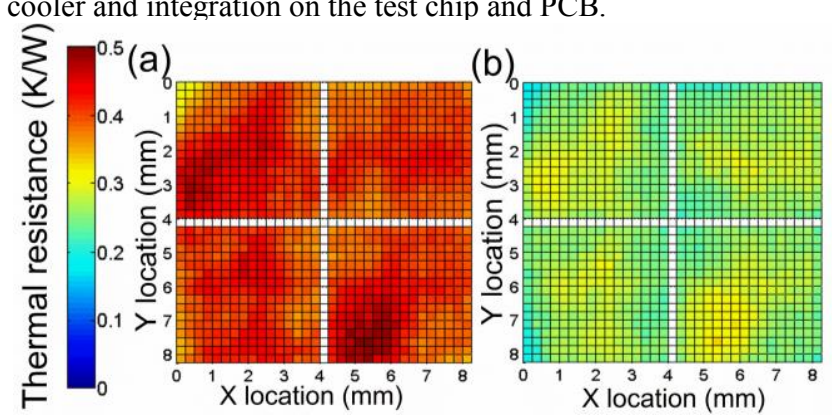

Fig. 11. Thermal resistance comparison based on the chip temperature distribution measurements for the $4 \times 4$ array cooler with a flow rate of $280 \mathrm{~mL} / \mathrm{min}$ (a) and $600 \mathrm{~mL} / \mathrm{min}$ (b).
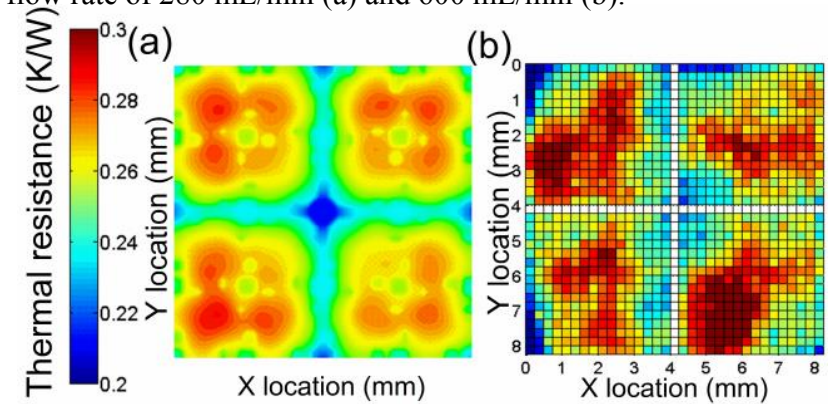

Fig. 12. CFD modeling (a) and measurement (b) results of the chip thermal resistance for the $4 \times 4$ array impingement cooler with a flow rate of $600 \mathrm{~mL} / \mathrm{min}$.
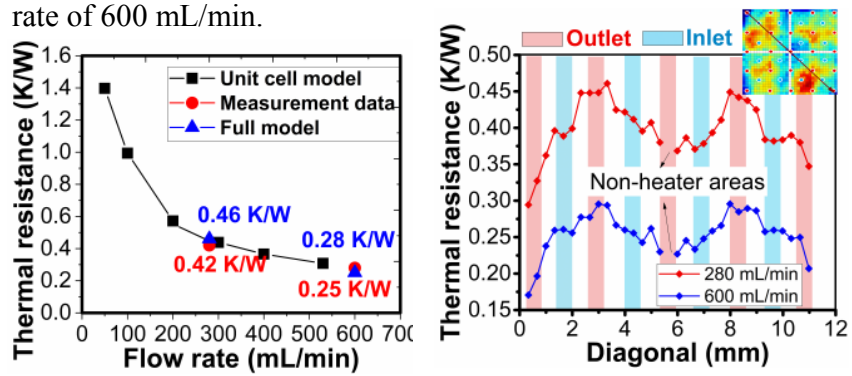

Fig. 13. Comparison between Fig. 14. Measured temperature the experimental results and the map corresponds to inlets and unit cell and full cooler model- outlets nozzle pattern. ing results.

\begin{tabular}{|c|c|}
\hline $\begin{array}{c}\text { Demonstrator } \\
\text { dimensions }\end{array}$ & $\begin{array}{c}\text { Mechanical } \\
\text { machining }\end{array}$ \\
\hline Nozzle array & $4 \times 4$ \\
\hline Inlet diameter & $450 \mu \mathrm{m}$ \\
\hline Outlet diameter & $600 \mu \mathrm{m}$ \\
\hline Cavity height & $\approx 300 \mu \mathrm{m}$ \\
\hline $\begin{array}{c}\text { Nozzle plate } \\
\text { thickness }\end{array}$ & $3 \mathrm{~mm}$ design \\
\hline Plenum height & $2 \mathrm{~mm}$ \\
\hline $\begin{array}{c}\text { Cooler size } \\
\text { XYZ }\end{array}$ & $\begin{array}{c}46 \times 46 \times 13 \\
{ }^{3}\end{array}$ \\
\hline
\end{tabular}

Table 2. Dimensions of the cooler demonstrator.
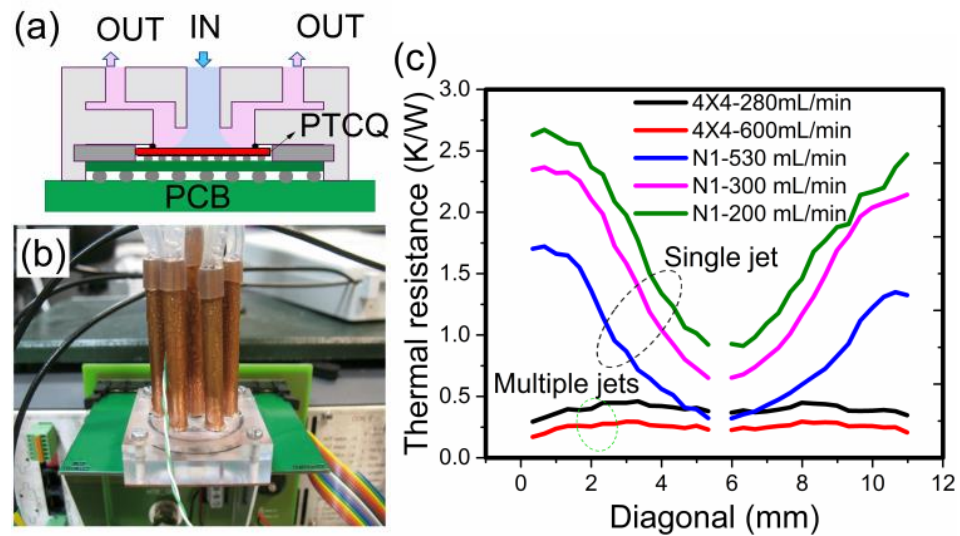

Fig. 15. a) Demonstrator schematic and b) photograph of the single jet cooler. c) Comparison of the measured temperature profiles for the cases of single jet cooler and the multi jet $4 \times 4$ array cooler.

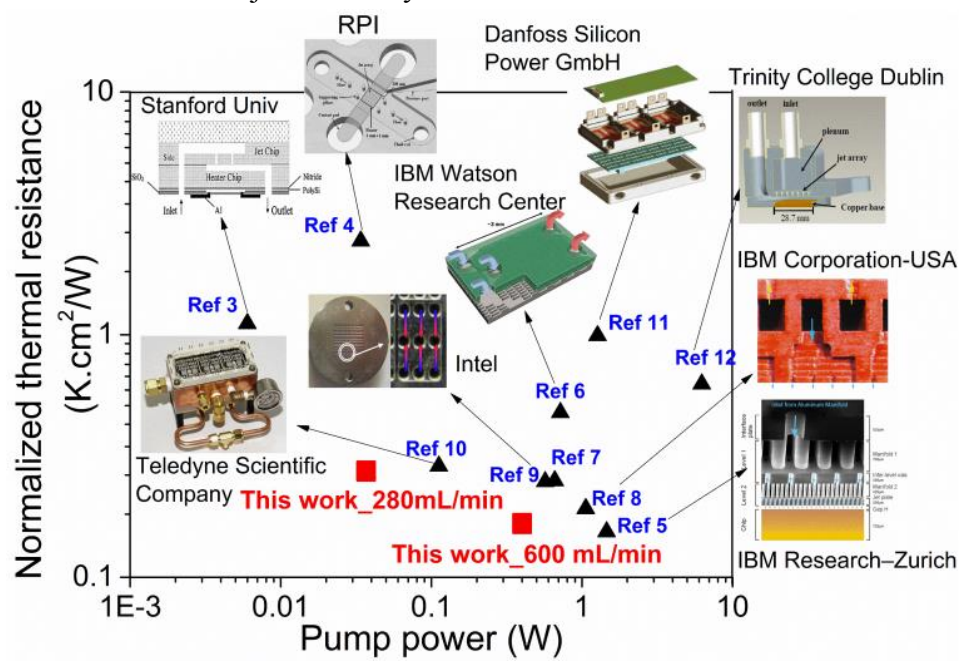

Fig. 16. Benchmarking of the thermal performance of this work with literature data with respect to achieved thermal resistance and required pump power. The two measurement data (Red Square) shown in this figure are based on the fabricated imec 3D-shaped polymer cooler with flow rate of $280 \mathrm{~mL} / \mathrm{min}$ and $600 \mathrm{~mL} / \mathrm{min}$. 